\title{
Macroergomonics' contribution to the effectiveness of collaborative supply chains
}

\author{
Sandra Mejias Herrera ${ }^{\mathrm{a},}{ }^{*}$, Luisa Huaccho Huatuco ${ }^{\mathrm{b}}$ \\ ${ }^{a}$ Departamento de Ingeniería Industrial, Universidad Central "Marta Abreu” de Las Villas, Prolongación de \\ Colón Edif. 3 apt. 2 Santa Clara, Villa Clara Cuba. \\ ${ }^{b}$ University of Leeds, Leeds University Business School, Woodhouse Lane, Leeds, LS2 9JT, UK \\ lh2@lubs.leeds.ac.uk
}

\begin{abstract}
This article presents a conceptual model that combines Macroergonomics and Supply chain. The authors combine their expertise on these individual topics, building on their previous research. The argument of the paper is that human factors are key to achieve effective supplier-customer collaboration. A conceptual model is presented, its elements and their interactions are explained. The Content-Context-Process is applied as a departing point to this model. Macroergonomics aspects considered are: a systemic approach, participatory ergonomics, formation of ergonomics teams and evaluation of ergonomics projects. The expected outcomes are: (a) improvement of production and productivity levels, (b) improvement of the product quality, (c) Reduction of absenteeism, (d) Improvement in the quality of work life (from the employees' perspective), and (e) increase in the employees' contribution rate of ideas for improvement. A case study was carried out at a vitroplant production organisation incorporating environmental aspects to obtain sustainable benefits.
\end{abstract}

Keywords: Macroergonomics, supplier-customer collaboration, effectiveness.

\section{Literature review}

It is rare the literature that covers the joint investigation of Macroergonomics and Supply Chain (Garcia Acosta and Lange Morales 2008). Hendrick (2008) defined Macroergonomics as the Human Factors/Ergonomics interface at organizational level. Siemieniuch and Sinclair (2002) state that ergonomics can provide an understanding on the complexity of business processes and their emergent behavior. They argue that supply chain processes in Small and Medium Enterprises (SME's) can be less of an issue because they have one site, their processes are co-located and there is only one dominant process, whereas for larger companies: operations can be on several sites (globally distributed), the process has to be tailored to accommodate these differences (regional, cultural and legal) among other reasons.

Previously these authors (Siemieniuch and Sinclair 2000) had pointed out that the identification of processes and the infrastructure on their own cannot provide the required behavior, i.e. it is people who produce the behavior. The ergonomics issues of importance in relation to supply chain they identified as being: control, communication, compatibilities and culture. Regarding communication, the role of information flows were discussed especially the case of 'imperfect information' and 'excluded information' in supply chain. It is in this supply chain context that 'trust' is paramount, i.e. the common understanding of terms and language, common goals and shared benefits as well as integrity in relationships. They stated that it is trust that glues the supply chain together in order to ensure cooperation, coordination, delivery on time and within budget.

According to Bayo-Moriones and Merino-Diaz de Cerio (2004) organizations that adopt an open and collaborative attitude are likely to do so both externally (with other companies) as well as internally (within their own company). Performance measures proposed are: product quality, productivity, on time

\footnotetext{
* Corresponding author. E-mail: smejias@uclv.edu.cu
} 
and in full dispatch and flexibility. The results of their research point out the different factors that facilitate collaboration: multinational groups, great number of competitors and size (the smaller the organization the better).

The conceptual model presented by Pettigrew and Whipp's (1991) starts with "Content, Context and Process" framework, which coincides with $\mathrm{Ho}, \mathrm{Au}$ and Newton's (2002) who emphasized the need to consider supply chain within Context-PracticePerformance. They argued that both research theory and the organizational studies could be valuable for an integral understanding of the problem (conceptualizing) and its subsequent operationalization and modeling.

The research proposes that it is possible to gain effectiveness of collaborative supply chains if the Macroergonomics focus and their variables in its design are considered. These include focusing on supplier-customer interaction at different levels, together with the elements taken into account by Pettigrew and Whipp's (1991): Content, Context and Process.

- The Content (the What?) refers to the objectives, purposes and targets of the supplier-customer collaboration. These are the information and material flows exchanged between supplier and customer. For example, in the case of information flows, it considers the information from the quote request to the payment of the final products. Whereas, in the case of material flows, this could be the dispatch/reception of products and inventory management.

- The Context (the Where?) refers to the environment in which the collaboration is embedded. For example, the type of supply chain within its economic, social and political environment. It is worth mentioning that the environment can be of internal (within the collaboration) or external (outside the collaboration) nature. For example, internally the type of contract, the contractual and normative relationships. Whereas externally, we could consider sustainability issues and environmental impact by including aspects such as: economic, political and cultural key characteristics, for example.

- The Process (the How?) refers to the actual implementation of the supplier-customer collaboration. Out of the three dimensions listed above, it is the Process that is the most difficult to tackle.

It is argued here that in order to make the Process of the Supplier-Customer collaboration effective, the following Macroergonomics aspects should be considered: (a) A systemic and integral approach, which departs from the identification and analysis of the variables that affect job roles, work systems and organizations within the supplier-customer collaboration. Then, the implementation of ergonomic projects which would allow solving and obtaining improvements in their effectiveness should follow.

(b) The participation of all people involved in the supplier-customer collaboration, independently of hierarchical level, i.e. Participatory Ergonomics supported by case studies and action research as a methodologies to implement the interventions in the learning organizations. This implies the involvement of employees at all levels as well as the management in the identification, analysis and improvement proposals.

(c) The establishment of ergonomics teams as an essential part of the establishment for the identification and analysis of improvement proposals. This complements the previous Macroergonomics aspects above since it is not possible to obtain effective results if people are not organized in ergonomics teams which are distinguished by their systemic an integral approach from the variables involved to the integral solutions.

(d) The evaluation of effectiveness of the ergonomic projects which could warrant continuity of the ergonomic practices, such as the evaluation of the impact of the improvements of the results obtained. This constitutes an opportunity to continue the actions of the ergonomic projects.

These Macroergonomics aspects should in turn provide the following expected outcomes (Mejias Herrera and Huaccho Huatuco, 2011): (a) improvement of production and productivity levels, (b) improvement of the product quality, (c) Reduction of absenteeism, (d) Improvement in the quality of work life (from the employees' perspective), and (e) increase in the employees' contribution rate of ideas for improvement.

A common missing element in previous macroergonomic programmes was the evaluation of effectiveness. Some authors, such as Shannon and Guastello (1997) indicated that sometimes interventions cause more harm than good. Because of this it is necessary that programmes have some measure of their effects (Hendrick 2003, 2008; Tuncel et al. 2008).

This paper proposes a Macroergonomics Intervention Programme in a vitroplant production organisation for the improvement of working systems, emphasising the combination of two topics of the au- 
thors' research interests: Macroergonomics and Supply chains.

The motivation of the paper arised from the following question: How Macroergonomics could contribute to the effectiveness of collaborative supply chains?

\section{Methodological formulation}

The stated problem as well as the previous researches that have been carried out they urgently lead to define conceptual models to figure out procedures for macroergonomics interventions. The result has entailed to establish the following definition:

" A conceptual model should show a set of structured and interrelated concepts with a systemic perspective to establish the proposed macroergonomics procedure to obtain solutions for increasing well-being and productivity based on continuous improvement (Mejias Herrera, 2003).

The foundation for designing the model is introduced as follows:

- It avoids errors such as proposing changes without a systemic approach.

- It is not limited to the Macroergonomics focus.

- The future projection and adequate management system designed for ergonomic programmes should increase its effectiveness.

- Self-development of the organisation.

- Dialectic approach to express a continuous improvement process.

- Sets, organizes and manages the organisation based on processes and analyses each subprocess in detail, those that could improve the efficiency and performance level of the organisation's Human Capital.

The design of the model (Mejias Herrera, 2003) and the different applications carried out through the years, it allowed to observe the need to adapt the conceptual model to a consultancy procedure. The reasons are based on the modern organisations and researchers are facing a period of transformation which is evident in their increased use of consultants for intervention in different areas. This is due to the many problems faced by managers, who know that they need to "do something" but they do not know exactly "what" and "how" to do it, looking for solutions with the help of consultants.

The general design for the consultancy procedure with a macroergonomics focus se presenta en la Figura 1.
The Stage 1 "Definition of the ergonomic requirements" it refers to the Why? Where it focus on the stage in the definition of the object of study and the problem.

In the Stages $2-5$ the intervention is carried out by answering to the questions What to do? and How to do it?

The Stage 6 "Feedback and control" guarantees the cyclical maintenance of improvements.

Of great interest results the stage 1 based on the details of the consultancy procedure with emphasis on Ergonomic Work Analysis as it has been shown on the figure 2. Its application will meet the existing ergonomic demand starting by diagnosing the study's object system work.

In order to fulfill this objective, the starting point begins by establishing the initial definition of external and internal requirements referred as to the strategic context as well as to the problems related with the work system and the supply chain that provoques negatives effects in the enterprise, area or sector where it shall be done

The results are analyzed integrally obtaining one or more requirements, ergonomic controls or through a group effort. It must express the order of importance of requirements derived from choosing a method of weighting.

The analysis of work system continues where two important moments are carried out with the purpose of obtaining different results:

- Chose the area of study.

- Analysis of the working system with emphasis on Ergonomic Work Analysis. In the Figure 2 it has been highlighted with boxes of different colors steered by arrows, the conducting line that is carried out during the research to fulfill this moment.

Lastly, the analysis of results is done by integrating the causes of the detected problems systemically. The rest of the phases are also worth. Its adequate development will guarantee the benefits that are to be obtained with the ergonomic intervention

The stages 2 and 3 shows an intervention project with the design of the research adapted as a "suit that fits" to the problems detected in the area of study.

The initial proposal is presented to each of the ergonomic teams for its further discussion, its adequacy and its final discussion. 


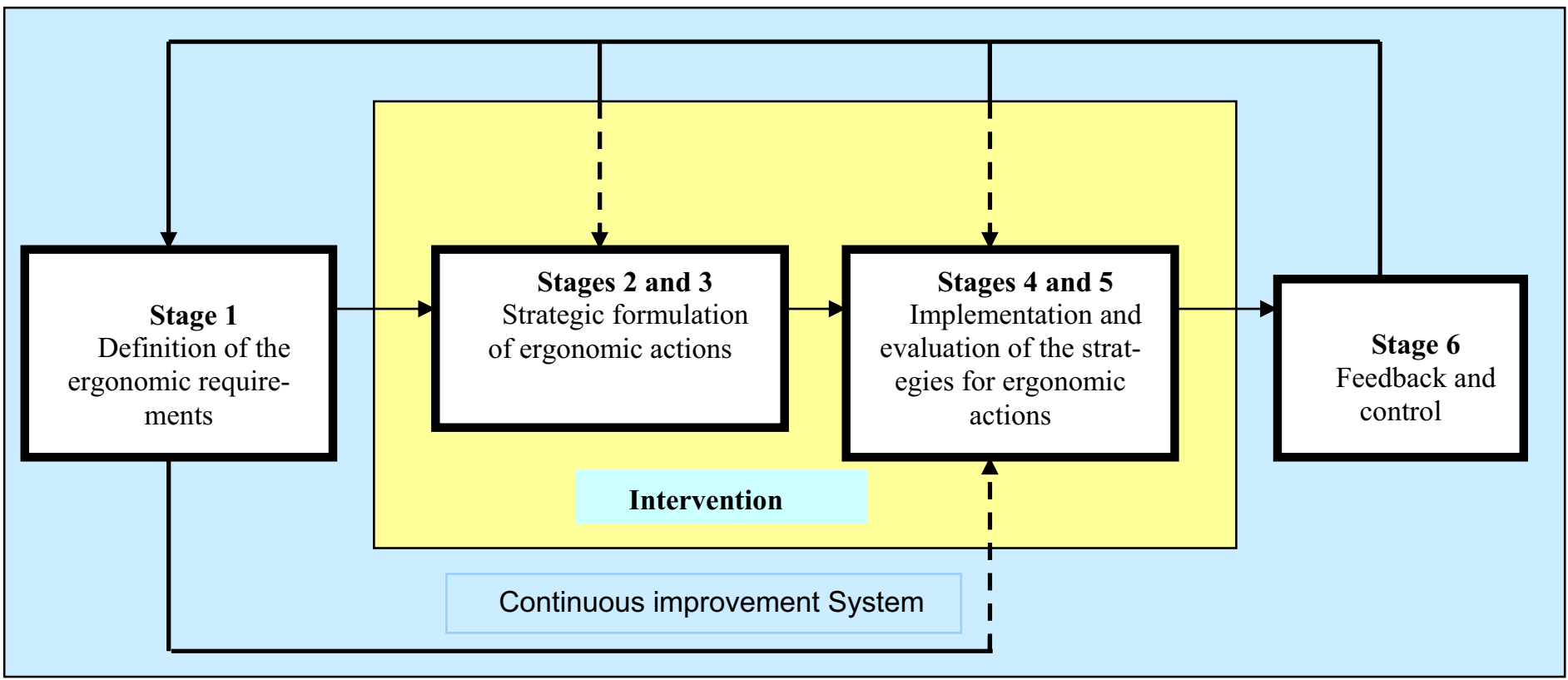

Figure 1. General design for the consultancy procedure with a macroergonomics focus

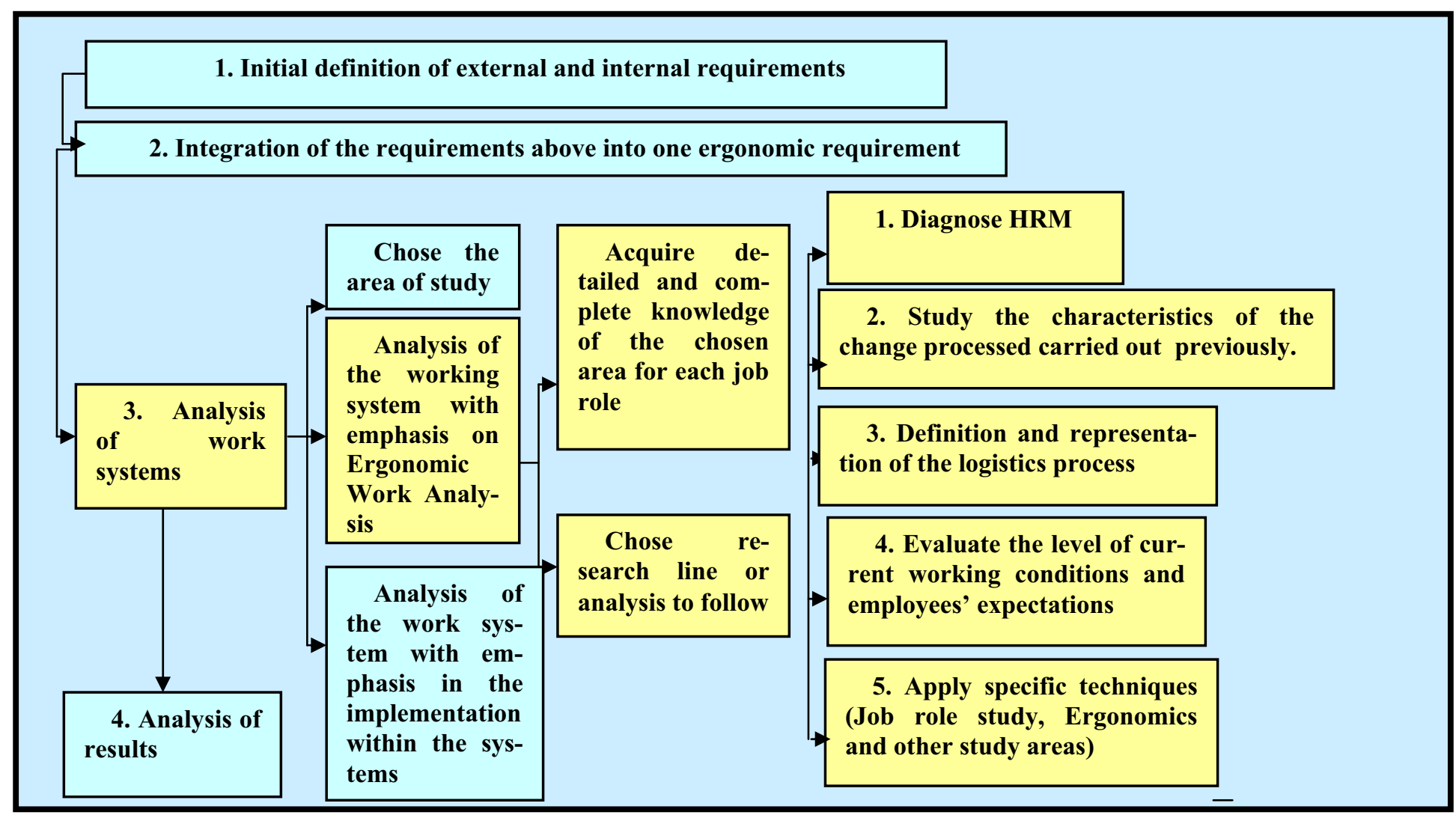

Figure 2. Definition of requirements and ergonomic needs (Stage 1) 
It is possible then to carry out the intervention (Stages 4 and 5) by adequating in its application the intervention project, if necessary, if the obtained results in the control work indicate that modification in the designed action is critical.

\section{Case study}

The Biotechnological Institute of Plants researches and produces vitroplants for national consumption and for export. The bio-factory has 34 employees and it is leading at national level due to its research results. However, in spite of the showing the best in the country's productivity result, utilisation of production capacity was not good.

Which are the defined ergonomic requirements?

To improve the quality of working conditions and the productivity level of the operations in the cabins of laminar fluid.

What was the response derived from the ergonomic programme?

The activities were planned in the intervention programme, including actions that allowed workers:

-To know the productive process developing different training courses and improving the relationships with management and participation in the decision making, such as the Redesign of he working system.

-To know the different consequences of repetitive and monotonous tasks, establishing and adequate design of breaks during the working day.

At the same time, a manual to evaluate the working conditions in the production area was designed. Additionally, the performance evaluation system was also designed. And the design of the cabins was improved in order to comply with ergonomics principles.

Thus, the chain analysis contributed to establish a system of recommendations related with the flow of the process and the exchange with the clients. This last aimed as an objective to elevate the effectiveness if the chain and its sustainability.

The aspects above affected the quality of working conditions, which made them perform poorly under the expectation of the employees (See Figure 3).

\section{Critical evaluation}

The benefits were analyzed and the results when finalizing the first intervention programme are shown in the Table 1 .
The analysis of the context and the flow of the chain also showed the satisfactory results in order to improve the relationship with the clients and also to have them connected with the conceived actions within the intervention program

A second intervention program that includes the experiences in this program is designed thus, a group of actions of superior levels are projected to improve the results as well as the process as in the working quality life.

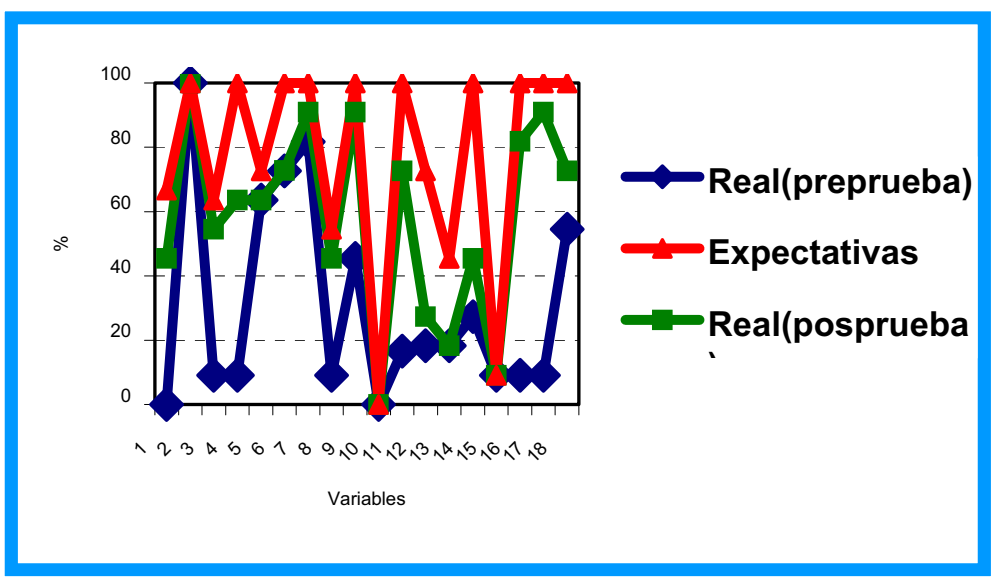

Figure 3. Real level and expectations regarding the working life.

Table 1.

Results the first intervention

\begin{tabular}{|c|c|c|}
\hline Groups & Indices & Results \\
\hline Efficiency & Efficiency of intervention index & $83 \%$ \\
\cline { 2 - 4 } & $\begin{array}{c}\text { Efficiency of number of trained } \\
\text { employees index }\end{array}$ & $100 \%$ \\
\hline Efficacy & $\begin{array}{c}\text { Improvement of the quality of } \\
\text { working conditions index }\end{array}$ & $65 \%$ \\
\cline { 2 - 4 } & $\begin{array}{l}\text { Index of Participatory management } \\
\text { in ergonomic activities by the ergo- } \\
\text { nomic team }\end{array}$ & $20 \%$ \\
\hline Effectiveness & Improvement of productivity index \\
\hline
\end{tabular}




\section{Conclusion}

The macroenorgomic approach applied the collaborative supply chains constitutes an important inter interdisciplinary link as to put into practice that comprises different satisfactory results in the quality of the working life, the productive results and the proper relations that are established within the chain supply.

The developed actions showed how a process design considering both the technical and human factors aspects, it is possible improve the competences of the employees and the competences of the processes at the end of the intervention.

\section{References}

Bayo-Morriones, A. and J. Merino-Díaz de Cerio. 2004. Employee Involvement: Its Interaction with Advanced Manufacturing Technologies, Quality Management, and Inter-Firm Collaboration. Human Factors and Ergonomics in Manufacturing. 14: 117-134.

García Acosta, G. and K. Lange Morales. 2008. Macroergonomics study of food sector company distribution centres. Applied $\mathrm{Er}$ gonomics. 39: 439-449.

Hendrick, H. W. 2003. Determining the cost-benefits of ergonomics projects and factors that lead to their success. Applied Ergonomics. 34: 419-427.

Hendrick, H. W. 2008. Applying ergonomics to systems: Some documented "lessons learned". Applied Ergonomics. 12: 418-426.

Ho, D. C. K., K. F. Au and E. Newton. 2002. Empirical research on Supply Chain Management: a critical review and recommendations. International Journal of Production Research. 40(17): 4415-4430.

Kerr, M. and L. Huaccho Huatuco. 2006. A framework to assess the effectiveness of collaborative supplier relationships. Proceedings of the 13th Annual International EurOMA Conference. Moving up the value chain. University of Strathclyde, Glasgow, 18th - 21st June 2006. Vol. I.. 995-1004.

Mejias Herrera, S. H. and L. Huaccho Huatuco. 2011. Macroergonomics Intervention Programmes: Recommendations for their design and implementation. Human Factors and Ergonomics in Manufacturing. 21: 227-243.

Mejias Herrera, S.. 2003. Tesis en opción del Grado Científico de Doctor en Ciencias Técnicas. Universidad Central "Marta Abreu" de Las Villas. Cuba.

Pettigrew, A. M. and R. Whipp. 1991. Managing change for competitive success. Oxford: Blackwell Business.

Shannon, H. and S. Guastello. 1997. Workplace Safety Measures What Can we Say About What Works? Proceedings of the 13th Triennial Congress of the International Ergonomics Association. Tampere, Finland: $650-653$.

Siemieniuch, C. E. and M. A. Sinclair. 2000. Implications of the Supply Chain for Role Definitions in Concurrent Engineering. Human Factors and Ergonomics in Manufacturing. 10: 251272.

Siemieniuch, C. E. and M. A. Sinclair. 2002. On complexity, process ownership and organizational learning in manufacturing organisations, from an ergonomics perspective. Applied Ergonomics. 33: 449-462.
Tuncel, S., A. Genaidy, R. Shell, S. Salern, W. Karwowski, M. Darwish., F. Noel and D. Singh. 2008. Research to Practice: Effectiveness of Controlled Workplace Interventions to Reduce Musculoskeletal Disorders in the Manufacturing EnvironmentCritical Appraisal and Meta-Analysis. Human Factors and Ergonomics in Manufacturing. 18: 93-124. 